\title{
Atuação do enfermeiro auditor nos processos de órteses e próteses e materiais especiais
}

\begin{abstract}
RESUMO|Objetivou-se descrever o papel do enfermeiro auditor nos processos que envolvem Órtese, Prótese e Material Especial (OPME) em ambiente hospitalar público ou privado. Trata-se de um estudo teórico-reflexivo que propõe uma discussão sobre os processos de OPME em território brasileiro, assim como as legislações vigentes, tanto na saúde suplementar quanto no atendimento gratuito e universal praticado pelo Sistema Úniaco de Saúde. Há uma necessidade de profissionais capacitados, com competência técnica e zelo pela segurança, para otimização no controle destes materiais, além de inibir práticas duvidosas e fraudulentas. Contribuindo com o controle e rastreabilidade dos materiais utilizados, garantindo o serviço prestado ao usuário e o monitoramento de qualidade do mesmo. Deste modo, conclui-se que a atuação do Enfermeiro Auditor nos processos de uso de OPME é primordial para que sejam cumpridas e respeitadas, conforme as normatizações e legislações vigentes, todas as etapas do processo, tanto nas instituições públicas ou privadas. Constatou-se também que poucas são as publicações científicas em âmbito nacional a respeito da temática.
\end{abstract}

Palavras-chaves: Auditoria de Enfermagem; Próteses e Implantes; Aparelhos Ortopédicos; Tecnologia de Alto Custo.

\begin{abstract}
The aim was to describe the role of the nurse auditor in the processes involving OPME in a public or private hospital environment. It is a theoretical-reflective study that proposes a discussion on the OPME processes in Brazilian territory, as well as the current legislation, both in supplementary health and in free and universal care practiced by the Unified Health System. There is a need for professionals trained, with technical competence and zeal for safety, to optimize the control of these materials, in addition to inhibiting doubtful and fraudulent practices. Contributing to the strict control and traceability of these inputs used, guaranteeing the service provided to the user and monitoring its quality. Therefore, it can be concluded that the role of the Nurse Auditor in the processes of use of OPME is essential for all stages of the process to be complied with and respected, in accordance with current regulations and legislation, both in public or private institutions. It was also found that there are few scientific publications nationwide on the subject.
\end{abstract}

Keywords: Nursing Audit; Prostheses and Implants; Orthotic Devices; Technology, High-Cost.

RESUMEN | El objetivo era describir el papel del auditor de enfermería en los procesos que involucran a OPME en un entorno hospitalario público o privado. Es un estudio teórico-reflexivo que propone una discusión sobre los procesos de OPME en el territorio brasileño, así como la legislación actual, tanto en salud complementaria como en atención gratuita y universal practicada por el Sistema Único de Salud. Se necesitan profesionales. capacitados, con competencia técnica y celo por la seguridad, para optimizar el control de estos materiales, además de inhibir prácticas dudosas y fraudulentas. Contribuyendo al estricto control y trazabilidad de estas entradas utilizadas, garantizando el servicio prestado al usuario y monitoreando su calidad. Por lo tanto, se puede concluir que el papel de la Enfermera Auditora en los procesos de uso de OPME es esencial para que se cumplan y respeten todas las etapas del proceso, de acuerdo con las regulaciones y la legislación vigente, tanto en instituciones públicas como privadas. También se descubrió que hay pocas publicaciones científicas en todo el país sobre el tema.

Descriptores: Auditoría de Enfermería; Prótesis e Implantes; Aparatos Ortopédicos. Tecnología de Alto Costo.

\section{Graziela Aparecida Mendieta}

Enfermeira. Especialização em Auditoria e Gestão da Qualidade aos Serviços de Saúde da Faculdade Novoeste. Campo Grande - MS.

\section{Adaiele Lucia Nogueira Vieira da Silva \\ Enfermeira. Doutoranda pelo Programa de Pós-Graduação em Saúde e Desenvolvimento na Região Centro-Oeste pela Universidade Federal de Mato Grosso do Sul (UFMS). Mestra em Enfermagem. Docente no curso de Especialização em Auditoria e Gestão da Qualidade aos Serviços de Saúde na Faculdade Novoeste, Campo Grande - MS.}

\section{Tatiane Novais Dantas}

Médica - Especialização em Neurologia Clínica. Pós-graduação em Medicina do Sono e Medicina do Trabalho. Especialização em Auditoria e Gestão da Qualidade aos Serviços de Saúde da Faculdade Novoeste. Campo Grande - MS.

\section{Cleuzieli Moraes dos Santos}

Enfermeira. Mestre em Saúde da Família. Especialista em Gestão de Políticas de Saúde Informadas por Evidências; Gestão da Clínica nas Regiões de Saúde; Auditoria de Sistemas e Serviços de Saúde; e Saúde Pública e Saúde da Família. Docente e coordenadora no curso de Especialização em Auditoria e Gestão da Qualidade aos Serviços de Saúde na Faculdade Novoeste, Campo Grande - MS.

\section{Rosely Almeida Souza}

Enfermeira. Doutoranda no curso PósGraduação em Saúde e Desenvolvimento na Região Centro-Oeste pela Universidade Federal de Mato Grosso do Sul (UFMS).

\section{Willian Alburquerque de Almeida}

Enfermeiro. Doutorando pelo Programa de Pós-graduação em Saúde e Desenvolvimento na Região Centro-Oeste da Universidade Federal de Mato Grosso do Sul - UFMS. Professor do curso de enfermagem da Fundação Educacional de Andradina - FEA - Andradina - SP.

Recebido em: 27/03/2020

Aprovado em: 28/03/2020 
INTRODUÇÃOO

A s grandes transições ocorridas desde o século passado (XIX) aos dias atuais vêm trazendo impactos importantes nos eixos econômicos, políticos, sociais e culturais; inclusive, com evoluções das tecnologias que mudaram o perfil e o estilo de vida das pessoas, sobretudo, no contexto saúde-doença ${ }^{(1)}$.

A partir dessa demanda, os processos de saúde-adoecimento têm sofrido alterações devido aos complexos e múltiplos fatores dessas inovações ${ }^{(1)}$.

Assim, nos últimos anos, o perfil de morbimortalidade da população brasileira está relacionado com o aumento de números de óbitos causados por doenças crônicas. Nessa lógica, as doenças cardiovasculares e seus fatores de riscos, a hipertensão arterial e a diabetes de mellitus, refletem o estilo de vida que as pessoas vivem ${ }^{(2)}$.

As Doenças Cardiovasculares (DCV), classificadas como doenças crônicas, são uma das maiores causadoras de óbito na população mundial, gerando impacto social e econômico. Como consequências acometidas por estas doenças, pode-se elencar: mortes prematuras, incapacidades laborais e inatividade no mercado, diminuição da mão de obra da população ativa e da renda familiar, e gastos em orçamentos públicos com internação, tratamento clínico e cirúrgico ${ }^{(3)}$.

Além disso, há um aumento no número de indivíduos submetidos à procedimentos cardiológicos e vasculares, eletrofisiológicos e hemodinâmicos. Assim como, angioplastias, cirurgias abertas ou percutâneas com uso de Órteses e Próteses e Materiais Especiais (OPME), que auxiliarão no tratamento e recuperação do incapacitado acometido por estas doenças ${ }^{(3)}$.

Neste contexto, o cenário necessita de todo o conhecimento específico e tecnológico para se garantir a adequada assistência prestada, bem como a gestão e o controle financeiro. Desse modo, nos serviços de saúde, tem-se a figura indis- pensável do enfermeiro auditor, que vem contribuindo para o controle financeiro e à garantia da qualidade dos serviços prestados e executados ${ }^{(4)}$.

O enfermeiro, por meio do Exercício Legal da Profissão, pode participar das atividades nas instituições relacionadas à saúde, tanto no planejamento, como na organização, coordenação, execução, consultoria, auditoria e emissão de pareceres, conforme regulamentado pelo Decreto n. ${ }^{\circ}$ 9.4406, de 8 de junho de $1987^{(5)}$. Já o enfermeiro auditor é habilitado a executar, de maneira autônoma, o planejamento, execução e avaliação dos serviços prestados na área de saúde, bem como coibir prejuízos na assistência ao usuário, inclusive no âmbito econômico financeiro, conforme Resolução n. ${ }^{\circ} 266$, de 5 de outubro de 2001, do Conselho Federal de Enfermagem - COFEN(6).

Pela exposição da problemática, o presente estudo visou responder as seguintes perguntas: Quais os processos que envolvem OPME no Brasil? Qual atuação do enfermeiro auditor neste cenário? Diante disso, objetivou-se descrever o papel desse profissional nos processos que envolvem OPME em ambiente hospitalar público ou privado.

\section{METODOLOGIA}

Trata-se de um estudo teórico-reflexivo que propõe uma discussão sobre os processos de OPME em território brasileiro, assim como as legislações vigentes, tanto na saúde suplementar quanto no atendimento gratuito e universal praticado pelo Sistema Único de Saúde (SUS). A pesquisa foi realizada nos meses de junho de 2019 a janeiro de 2020.

Os critérios de inclusão foram: publicações em periódicos nacionais e internacionais; temática de OPME, estudos realizados em território brasileiro, em português, com textos completos de disponibilidade pública; publicados no período de 2009 a 2019. Os critérios de exclusão para a presente proposta de estudo foram: artigos repetidos em mais de uma base de dados, os quais foram considerados somente uma vez, os editoriais, e os estudos que apesar de apresentarem os termos selecionados não respondiam a questão norteadora.

A coleta de dados ocorreu nas seguintes bases de dados: Google acadêmico, Scientific Eletronic Library On Line (SciELO) e páginas eletrônicas do Ministério da Saúde e Agência Nacional da Saúde Suplementar (ANS). Foram utilizados os descritores: "Auditoria de Enfermagem", "Órtese", "Aparelhos Ortopédicos" e "Tecnologia de Alto Custo". Salienta-se que foram utilizados os termos OPME (Órtese, Prótese e Materiais Especiais) e processos de alto custo na saúde, pois não há descritores para os mesmos.

\section{DISCUSSÃO}

Com a mudança no modelo assistencial de saúde, o Estado buscou promover ações direcionadas a estes serviços, sendo garantido pelo direito constitucional, a todos brasileiros, o acesso aos princípios da universalidade, integridade e equidade, promovido e realizado por órgãos públicos, privados e conveniados, mediante o SUS que fora regulamentado pela Lei n. ${ }^{\circ} 8.080$ de $1990^{(7)}$.

As três esferas do governo (Federal, Estadual e Municipal) consolidam estas ações do SUS e regem suas competências em controlar, fiscalizar, procedimentos e produtos no âmbito da saúde, com direcionamento dos orçamentos, execução e financiamento expressos pela Lei Orgânica n. ${ }^{\circ} 8.142$ de $1990^{(7)}$.

O direito em fornecer o acesso à saúde para a população, por meio do SUS, possibilitou o incremento de evoluções científicas e tecnológicas que desenvolvem e contribuem na área da saúde, local onde se mais direciona recursos financeiros, com elevados gastos, pelos serviços prestados com qualidade e efetividade. Desse modo, torna-se imprescindível, com a implementação das demandas tecnológicas, a qualificação de gestores com conhecimento e controle dos recursos ${ }^{(8)}$. 
Neste contexto, o controle sanitário e de responsabilidade técnica para os materiais e insumos relacionados à área da saúde, iniciou-se, a partir da Lei n. ${ }^{\circ}$ 5.990, de 17 de dezembro de $1973^{(9)}$, sendo fortalecida pela Lei n. ${ }^{\circ} 9.782,26$ de janeiro de 1999, E se constitui em um conjunto de ações que regula, normatiza, controla e fiscaliza a procedência sanitária dos materiais relacionados à área da saúde, com finalidade de promover e garantir saúde da população(10).

A forma garantida do tratamento de alta complexidade com internações hospitalares associadas às intervenções recomendadas e com o uso de materiais especiais necessitou de ações especificadas e complexas para uso dessa demanda tecnológica nas instituições de saúde ${ }^{(11)}$.

O Grupo de Trabalho Interinstitucional (GTI), criado pela Portaria Interministerial n. ${ }^{\circ}$ 38, de 8 janeiro de 2015. Sendo instituído com o propósito de reestruturar e tornar transparente todas as informações relacionadas à utilização dos dispositivos médicos (OPME), desde produção ao processo final, o usuário ${ }^{(12)}$.

O referido GTI traz a seguinte definição "Órtese: todo dispositivo permanente ou transitório, utilizado para auxiliar as funções de um membro, órgão ou tecido, evitando deformidade, ou progressões e/ ou compensando insuficiências funcionais. Prótese: todo dispositivo permanente ou transitório que substitui total ou parcial um membro, órgão ou tecido". Observa-se que as instituições de saúde, públicas ou privadas, tiveram um grande aumento na utilização de OPME como forma de demanda tecnológica e auxílio das intervenções diagnósticas e terapêuticas ${ }^{(12)}$.

Conforme o estudo realizado pelo GTI, os profissionais da enfermagem são reconhecidos pelas suas atividades nas inovações tecnológicas e nos diagnósticos e pelo estudo e avaliação do custo-efetividade nos processos que envolvam o uso dessas OPME ${ }^{(12)}$.

Processo de aquisição e controle do uso de OPME e sua rastreabilidade
No Brasil, o gasto com uso de OPME, em 2014, ultrapassou os 19,7 bilhões de reais, isto se dá pelo recorrente avanço tecnológico na área da saúde relacionado com estes produtos, que auxiliam nos diagnósticos, tratamentos, reabilitações terapêuticas e impulsionam os mercados e fornecedores em atenção ao desenvolvimento, fabricação e comercialização ${ }^{(12)}$.

A preocupação dos gestores das instituições em saúde em atender, com efetividade e eficácia, a garantia da qualidade da assistência prestada e em manter a relação custo-benefício, que onera o setor financeiro, requer organização, seriedade e conhecimento para atender todo o fluxo do processo, além de habilidade para gerir com imparcialidade os assediadores (fornecedores e fabricantes) que desejam induzir profissionais ao direcionamento de solicitação de seus materiais, injustiçando assim, as concorrências dos materiais melhores e com a qualidade ${ }^{(13)}$.

Destaca-se que no SUS a tabela de OPME do Sistema de Gerenciamento de Tabelas de Procedimentos (SIGTAP), instituída pela Portaria GM/MS n. ${ }^{\circ}$ 2.448, de 6 de novembro de 2007, traz as descrições, compatibilidades e valores dos materiais, entre outros ${ }^{(14)}$.

O processo de aquisição das OPME inclui diversas fases, que inicia-se pelas especificações técnicas até a confirmação de utilização, verificação da veracidade das informações e pela boa aquisição do produto; com rastreabilidade e atendimento de paciente/usuário ${ }^{(12)}$.

As aquisições de OPME são de responsabilidade do gestor hospitalar ou responsável, conforme procedimentos de alta complexidade ou auxílio diagnóstico, desde a confecção, comercialização e registro ${ }^{(15)}$. Nas instituições hospitalares, o processo que envolve o uso de OPME tem como foco a gestão do fluxo, visando garantir o controle e o monitoramento desses insumos. A Portaria SAS/MS n. ${ }^{\circ} 403$, de 7 de maio de 2015, atualmente revogada pela Por- taria SAS/MS n..$^{\circ} 1.302$, de $1^{\circ}$ de agosto de 2017, regulamenta as etapas de todo o processo, sendo estas abordadas neste estudo: aquisição/compra, fornecimento, distribuição, utilização, controle e rastreabilidade de OPME ${ }^{(16)}$.

Uma das recomendações do GTI é de realizar a análise do perfil institucional quanto à necessidade de se adquirir as OPME, considerando as evidências científicas e o controle de tecnovigilância, evitando qualquer tipo de conflito de interesses. Para tanto, faz-se necessário se constituir uma comissão específica para análise técnica, de desempenho, de qualidade e de rastreabilidade do produto $^{(16)}$.

Ademais, as compras/aquisições devem ser adequadas com a caracterização do objeto e de recursos orçamentários, e apropriadas às padronizações; compatibilidades; sem indicação de marcas; contendo especificações, assistências técnicas e manutenções; garantidas pelas quantidades por estimativas técnicas e sem deterioração por armazenamento; e com balizamento de registro de preços compatíveis no mercado e de livres concorrências ${ }^{(17)}$.

Referente à aquisição, a instituição de saúde deve realizar uma previsão da quantidade de material para atender sua demanda, hospitalar e ambulatorial, com planejamento nas especificações técnicas e parâmetros de qualidade das OPME, que devem estar registradas na Agência Nacional de Vigilância Sanitária - Anvisa ${ }^{(16)}$.

É importante salientar que, na esfera pública, todo processo que envolve obras, serviços, publicidades, compras, concessões, permissões, e quaisquer ações contratadas com terceiros, devem ser regidas pela Lei n. ${ }^{\circ}$ 8.666, de 21 de junho de 1993, que contempla as regras gerais e normas de licitação e contratos administrativos $^{(17)}$.

Nessa lógica, o Termo de Referência (TR), documento que expressa as informações do objeto a ser contratado, no caso, OPME, serve de base para a aquisição do mesmo e deve conter de forma clara e objetiva as informações sobre o 
material, de acordo com as normas da Advocacia Geral da União (AGU). O TR deverá, por exemplo, conter cláusulas que vinculem o fornecedor sobre o regime de comodato e a sua obrigatoriedade em realizar as trocas de componentes que não foram utilizados, após a sua validade e/ou término da sua garantia ${ }^{(16)}$.

Por fim, as licitações serão realizadas na forma de Pregão, preferencialmente eletrônico, e processadas no Sistema de Registro de Preços, de modo a garantir que seja cumprido aquilo que esteja no TR. A formalização do vencedor é realizada por meio de contrato e a aquisição mediante a emissão da Nota de Empenho (NE). As NE e as Notas Fiscais (NF) devem conter todas as informações pertinentes e conformidades, para que sejam registradas no Sistema Integrado Administração Financeira do Governo Federal (SIAFI), para posterior liquidação da $N F^{(16)}$.

Os materiais destinados ao uso na saúde devem conter um registro técnico para fins de cadastro na Anvisa, com informações de: se o material é apenas um acessório ou componente, nome comercial, composição e identificação com etiquetas de rastreabilidade, conforme a Regulamentação da Diretoria Colegiada (RDC) n. ${ }^{\circ}$ 14, de 5 de abril de $2011^{(18)}$.

Estas etiquetas deverão conter o resumo de todas as informações do material, a saber: lote; registro do material na ANVISA; nome comercial, código do fabricante ou importador e código do produto no sistema, além de invólucro especificando sua forma e instruções de uso, no que tange à RDC n. ${ }^{\circ} 14 / 2011^{(18)}$.

Quanto ao recebimento, as OPME adquiridas deverão ser armazenadas em almoxarifados ou depósitos adequadamente preparados, com acessos restritos à circulação de pessoas, podendo ser permanente ou temporário ${ }^{(16)}$.

Além disso, devem ser realizados os registros das informações nos sistemas da instituição, por meio das descriminações das NE, com especificações dos materiais, códigos, validades, lotes, quantidades, valores da NF e NE, números da NF, Cadastro Nacional Pessoa Jurídica (CNPJ) dos fornecedores, razão social dos fornecedores e fabricantes, para que sejam verificadas as veracidade das informações ${ }^{(16)}$.

Convém destacar que no setor de almoxarifado central, as OPME serão analisadas e imediatamente processadas, para que atendam às solicitações com presteza e celeridade de fornecimento. Além disso, ao ser encaminhado ao centro cirúrgico, o acompanhamento da OPME deverá ser realizado por um profissional circulante de sala, que averiguará o seu uso, realizando a conferência dos insumos utilizados e registrando em formulários de consumo específico da instituição, item a item. Ademais, as OPME não utilizadas deverão retornar ao almoxarifado central, local de controle rigoroso e de armazenamento ${ }^{(16)}$.

No que tange à utilização, todas as OPME e Dispositivos Médicos Implantáveis (DMI) deverão ser de supervisão e responsabilidade do Diretor Técnico das instituições de saúde e do médico que indicou e realizou o procedimento, conforme regulamentado pelo Conselho de Federal de Medicina (CFM), por meio da Resolução n. ${ }^{\circ}$ 1.804, 20 de dezembro de $2006^{(19)}$.

Ainda, conforme a Resolução do Conselho Federal de Odontologia (CFO), n. ${ }^{\circ} 115$, de 3 abril de 2012, também cabe ao especialista cirurgião determinar a utilização de OPME em seus procedimentos e instrumentais compatíveis, de acordo com especificidade, tamanho, tipo e o material ${ }^{(20)}$.

Assim sendo, o fornecimento de OPME deverá ser feito mediante a solicitação do profissional que realizará o procedimento e que necessite do uso, antecipadamente até 48 horas, quando eletivo, contendo todos os dados do paciente em um formulário específico da instituição, tais como: nome completo, prontuário, material especificado, nome do procedimento e nome do profissional responsável ${ }^{(16)}$.
No âmbito do SUS, os pacientes que estão internados devem possuir Autorização de Internação Hospitalar (AIH) que justifique a necessidade do uso da OPME, com os devidos códigos que atendam às solicitações dos procedimentos cirúrgicos ${ }^{(16)}$.

O registro da utilização e o controle do consumo deverão ser feitos mediante a descrição dos materiais utilizados, anexando as etiquetas de rastreabilidade e conservando os invólucros das embalagens no formulário específico. Posteriormente, o registro deverá ser encaminhado ao setor responsável para a conferência e faturamento dos itens utilizados junto com a $\mathrm{AlH}^{(16)}$.

Nas instituições privadas, a Agência Nacional de Saúde (ANS) determina e disponibiliza o uso de OPME com intervenção cirúrgica ou não, de acordo com os procedimentos, e materiais que constam nas relações de Rol de Procedimentos, para que as operadoras de planos de saúde atendam seus beneficiários conforme a solicitação do especialista assistente ${ }^{(21)}$.

Conforme a Normativa Regulamentadora (NR) n. ${ }^{\circ} 428$, de 7 de novembro de 2017, para o fornecimento de OPME dos procedimentos disponibilizados no Rol da ANS, os profissionais solicitantes, estes: médicos assistentes ou cirurgiões dentistas, devem realizar as descrições dos materiais, com as características, quantidades e marcas registrados em um formulário específico de cada convênio ou operadora de saúde ${ }^{(22)}$.

O respectivo formulário deverá conter justificativa clínica do solicitante, o uso e a necessidade de OPME, além da informação de pelo menos três marcas diferentes devidamente reconhecidas e aprovadas pela Anvisa e que atendam às especificações técnicas; para que seja feita uma cotação com os fornecedores e, assim, eleger os que tiverem em melhores condições para atender as especificidades do procedimento do solicitante. Nesta fase, também se tem a necessidade de realização de autori- 
zação prévia da operadora para realização do procedimento(21).

Já a NR n. ${ }^{\circ} 424$, de 26 de junho de 2017, sinaliza ainda que quando houver divergência, entre a operadora e o profissional assistente, na disponibilidade do material solicitado para uso técnico-assistencial na realização do evento em saúde ou cirurgia, deve-se compor uma junta de profissionais para se garantir a resolutividade da demanda ${ }^{(21)}$.

Esta junta constituir-se-á pelo solicitante médico ou cirurgião dentista, um membro da operadora e um desempatador, que adotarão critérios de liberação e de avaliação sobre o emprego da utilização e de fornecimento da OPME, de acordo com que se encontra na lista de Rol de Procedimentos e de registro na Anvisa, ressalvando, os procedimentos de urgência e emergência ${ }^{(21)}$.

Não obstante, deve-se considerar a rastreabilidade de todas as OPME como garantia de segurança ao usuário. Neste cenário, alguns equipamentos, aparelhos

e insumos utilizados na aplicação médica, odontológica, na prevenção, tratamento e reabilitação e que utilizam formas de preservação e esterilização em sua conservação ficam proibidos reprocessamentos, conforme a regulamentação da Diretoria Colegiada n. ${ }^{\circ}$ 156, de 11 de agosto de $2006^{(23)}$.

Destaca-se ainda, a necessidade de se disponibilizar, no mínimo, 03 etiquetas de OPME para serem anexadas, obrigatoriamente, no prontuário, na ficha de consumo e no Registro Geral Operatório (RGO). Elas devem conter um resumo de todas as informações técnicas pertinentes ao registro na Anvisa, como lote, numeração, nome comercial e fabricante, conforme Resolução RDC n. ${ }^{\circ}$ 14, de 05 de abril de $2011^{(18)}$.

Já a Resolução RDC n. ${ }^{\circ} 232$, de 20

de junho 2018, normatiza que as etiquetas dos materiais específicos, como implantes de stents coronários e próteses de quadril e joelho, devem conter código de barras de rastreabilidade com as informações de identifica- ção, data de validade e número de série ou lote, a fim de facilitar a identificação eleitura eletrônica ${ }^{(24)}$.

Ainda em conformidade com esta RDC, as etiquetas devem ser anexadas, no mínimo, ao prontuário, ao documento ou cartão a ser entregue ao paciente e na Nota Fiscal do produto. Ademais, os fornecedores são obrigados a alimentar o sistema de Registro Nacional de Implantes (RNI) com as informações dessas OPME(24).

Os procedimentos realizados no SUS e na Saúde Suplementar deverão estar cadastrados no RNI com informações das intervenções cirúrgicas e localização dos materiais utilizados, produtos, serviços e profissionais envolvidos, de modo a minimizar os riscos ao usuário e contribuir para as possíveis correções ${ }^{(12)}$.

Já para procedimentos com uso de OPME não cirúrgicas, recomenda-se que o usuário deva ser acompanhado por uma equipe de reabilitação, para evitar possíveis complicações. Além disso, sua dispensação deve ser registrada em formulário específico com recomendação ao uso e com assinatura de um usuário ou responsável para, posteriormente, ser anexada ao prontuário ${ }^{(12)}$.

O Enfermeiro Auditor no Processo de OPME

O enfermeiro que detenha conhecimento dos processos de auditoria consegue inspecionar a qualidade fornecida dos materiais relacionados aos procedimentos e com valores cobrados ao usuário, atestando assim, sua confiabilidade $^{(4)}$.

Desse modo, as práticas assistenciais de enfermagem prestadas aos usuários contribuem para os controles de gastos e de perdas dos materiais, insumos e equipamentos, garantidas por meio de práticas que determinam a eficácia, efetividade e a qualidade e que são capazes de diminuir dúvidas relacionadas aos procedimentos, favorecendo assim, o controle financeiro e glosas desnecessárias ${ }^{(25)}$.

Devida à alta complexidade dos procedimentos e, consequentemente, da utilização de OPME, requer-se cuidados para se minimizar os possíveis erros e custos elevados, tanto para a instituição como para o usuário. Nesse sentido, o enfermeiro detém competência e segurança nas etapas do processo de alto custo, com controle rigoroso e minucioso, preparo, utilização, conferência, devolução e faturamento das mesmas ${ }^{(11)}$.

Deve-se considerar ainda que o enfermeiro com atuação na área de auditoria, que detenha conhecimento técnico alinhado ao das inovações tecnológicas, é capaz de avaliar os cuidados prestados ao usuário e o controle financeiro e contábil ${ }^{(4)}$. Sendo assim, este profissional atesta e garante a qualidade do serviço prestado por meio da análise dos prontuários e auditoria recorrente, reconhecendo inclusive erros e colocando a prática educativa nas correções apontadas, diminuindo os riscos aos usuários e prejuízos à instituição.

Neste cenário, estudos ainda apontam a existência de eminente deficiência das anotações de enfermagem na assistência prestada no centro cirúrgico, dificultando a análise da equipe de auditoria. Sabe-se que a enfermagem atua nos cuidados prestados ao paciente durante o transoperatório e que o tempo de permanência do paciente é relativamente curto; fatores estes que podem contribuir para a não priorização das anotações ${ }^{(26)}$. Desse modo, esta problemática traz grandes impactos na qualidade das informações registradas e na garantia da segurança do paciente.

Apesar disso, a literatura retrata os avanços, sobretudo, tecnológicos que possibilitaram melhoria e desenvolvimento na saúde, contudo, ainda se evidencia a disparidade de preços na comercialização de OPME e abusos visando o lucro aos profissionais envolvidos ${ }^{(27)}$.

Ao encontro com esta prerrogativa, pesquisas têm refletido a importância da atuação do enfermeiro em uma instituição de saúde e em todos por meio de ha- 
bilidades e competência técnica, inclusive, como coordenadores para áreas que requerem alta complexidade ${ }^{(25)}$.

Destaca-se que todos os processos que envolvem OPME são considerados de alto custo para qualquer instituição, sendo assim, a atuação do enfermeiro cumprirá todas as fases dos processos, desde a conservação, manuseio, devoluções até seu faturamento, por meio da análise da adequada utilização e da garantia de segurança e qualidade da assistência ${ }^{(11)}$.

Ainda, outros autores, sinalizam a problemática enfrentada pelos hospitais públicos em relação ao aprovisionamento completo para aquisição e atendimento das demandas, por não possuir ferramentas capazes de auxiliá-los na previsão da estimativa da demanda, além da morosidade dos processos de licitação que, por sua vez, influenciam na disponibilidade de materiais nestes depósitos ${ }^{(28)}$.

Desse modo, atualmente, as tecnologias de informações são grandes aliados aos processos de auditoria, por garantir agilidade nas pesquisas e demandas ${ }^{(29)}$. Neste contexto, o enfermeiro com suas competências técnicas e assistenciais contribuem para manter elo entre tecnologias e recursos financeiros da instituição; atuando de maneira ágil nos processos e garantindo a privacidade e a segurança de informações, dos usuários e da instituição de saúde.

\section{CONCLUSÃO}

O presente estudo possibilitou a análise dos processos que envolvem o uso de OPME como auxílio nas intervenções de saúde, nos avanços tecnológicos e na sua aplicação, favorecendo a recuperação do paciente, com melhorias na saúde e na qualidade de vida.

Sabe-se que o enfermeiro auditor é um profissional capaz de avaliar as práticas dos cuidados assistenciais, inclusive do retorno dos insumos não utilizados, por meio de análises de prontuários, RGO e de consumo de materiais. Assim, este profissional contribui com a minimização de possíveis práticas indevidas e fraudulentas e corrobora com o controle de gastos nas instituições de saúde por meio da adequada prática da gestão financeira e contábil, com a devida cobrança ao usuário ou ao serviço de saúde e de liquidação ao fornecedor.
Ao examinar o prontuário e realizar a conferência das etiquetas das OPME, anexadas como comprovação de uso, o enfermeiro auditor fortalece a atuação da equipe de saúde na garantia da qualidade da assistência prestada ao usuário, na segurança da rastreabilidade e na veracidade das informações do produto. Ademais, caso seja necessária à realização de um reparo ou de uma substituição, por falha do material, a rastreabilidade facilita a localização, garantindo assim, o direito ao usuário da resolubilidade do fato.

Considerados os materiais de alto custo, devido suas aplicações nas intervenções de alta complexidade, este estudo, com embasamento técnico-científico, evidenciou a importância da atuação do enfermeiro auditor, desde a aquisição e controle até a rastreabilidade das OPME.

Embora a divulgação pelas mídias seja crescente, no que se refere às atividades fraudulentas envolvendo as OPME, observou-se a carência de produção científica nacional e internacional frente à temática abordada. Desse modo, recomenda-se a produção de estudos envolvendo a atuação de auditores em todas as fases do processo, tanto em instituições públicas quanto nas privadas.

\section{Referências}

1. Ministério da Saúde, Secretaria de Vigilância em Saúde, Departamento de Vigilância de Doenças e Agravos Não Transmissíveis e Promoção da Saúde (BR). Política Nacional de Promoção da Saúde (PNPS). Anexo I da Portaria de Consolidação n. ${ }^{\circ} 2$, de 28 de setembro de 2017, que consolida as normas sobre as políticas nacionais de saúde do SUS [Internet]. Brasília (DF): MS, 2018 [acesso em 24 jan 2020]. Disponível em http://bvsms.saude.gov.br/bvs/publicacoes/politica_nacional_promocao_saude.pdf.

2. Zavatini MA, Obreli-Neto PR, Cuman, RKN. Estratégia saúde da família no tratamento de doenças crônico-degenerativas: avanços e desafios. Rev. Gaúcha Enferm [Internet]. 2010 [acesso em 24 jan 2020]; 31(4):647-54. Disponível em: https://www.scielo.br/scielo. php? script $=$ sci_arttext\&pid=S1 983-14472010000400006.

3. Siqueira MA, Filho AG, Land M. Cinco Anos no Brasil. Arq. Bras. Cardiol. [Internet]. 2017 mar [acesso em 24 jan 2020]; 109(1):3946. Disponível em http://www.scielo.br/pdf/abc/v109n1/pt_ 0066-782X-abc-20170068.pdf.

4. Ghizoni M, Vunha K, Guistina K. Atuação do enfermeiro que pratica auditoria hospitalar em um hospital de grande porte da região sul de Santa Catarina. Rev. Ciênc. Cidadania [Internet]. 2015 [acesso em 24 jan 2020]; 1(1). Disponível em: http://periodicos.
unibave.net/index.php/cienciaecidadania/article/viewFile/21/16. 5. Brasil. Decreto n. ${ }^{\circ} 94406$, de 8 de junho de 1987. Regulamenta a Lei 7498 , de 25 de junho de 1986, que dispõe sobre o Exercício da Enfermagem, e da outras Providências [Internet]. Brasília (DF): MS, 1989 [acesso em 24 jan 2020]. Disponível em: http://www. planalto.gov.br/ccivil_03/decreto/1980-1989/D94406.htm.

6. Conselho Federal de Enfermagem (BR). Resolução n. ${ }^{\circ}$ 266/2001, de 05 de outubro de 2001. Aprova as atividades do enfermeiro auditor. Brasília (DF): COFEN, 2001 [acesso em 24 jan 2020]. Disponível em: http://www.cofen.gov.br/resoluo-cofen-2662001_4303. html.

7. Brasil. Lei $n .{ }^{\circ} 8080$, de 19 de setembro de 1990. Dispõe sobre as condições para promoção, proteção e recuperação da saúde, a organização e o funcionamento dos serviços correspondentes e dá outras providências [Internet]. Brasília (DF): BR, 1990 [acesso em 24 jan 2020]. Disponível em: http://www.planalto.gov.br/ccivil_03/leis/L8080.htm\#art15.

8. Romanzini M. Análise de Fluxos e Processos de Gestão do Setor de Órteses, Próteses e Materiais Especiais em um Hospital Público no Rio Grande do Sul. Fundação Oswaldo Cruz [Internet]. Porto Alegre (RS). 2014 [acesso em 24 jan 2020]. Disponível em: https:// 
www.arca.fiocruz.br/handle/icict/35263.

9. Brasil. Lei n. ${ }^{\circ}$ 5991, de 17 de dezembro de 1973. Dispõe sobre o controle sanitário de comércio de drogas, medicamentos, insumos farmacêuticos e correlatos e dá outras providências. Brasília (DF): BR, 1973 [acesso em 24 jan 2020]. Disponível em: http://www. planalto.gov.br/ccivil_03/LEIS/L5991.htm.

10. Brasil. Lei . $^{\circ} 9782$, de 26 de janeiro de 1999. Define o Sistema Nacional de Vigilância Sanitária e cria a Agência Nacional de Vigilância Sanitária e dá outras providências. Brasília (DF): BR, 1999 [acesso em 24 jan 2020]. Disponível em: http://www.planalto.gov. br/ccivil_03/leis/L9782.htm.

11. Moraes C, Rabim E, Viegas K. Avaliação do processo de cuidado com órteses, próteses e materiais especiais. Rev Bras Enferm [Internet]. 2018; 71(3):1099-105, Porto Alegre - RS. DOI: http:// dx.doi.org/10.1590/0034-7167-2017-0031.

12. Ministério da Saúde (BR). Portaria Interministerial n. ${ }^{\circ} 38$, de 8 de janeiro de 2015. Institui o Grupo de Trabalho Interinstitucional sobre Órtese, Prótese e materiais Especiais (GTI- OPME), Relatório Final. Junho de 2015 [Internet]. Brasília (DF): MS, 2015 [acesso em 24 jan 2020]. Disponível em http://portalarquivos.saude.gov.br/ images/pdf/2015/julho/07/Relatorio-Final-versao-final-6-7-2015. pdf.

13. Souza M, Souza C, Cintra G. Glosa de Materiais Especiais em Um Hospital Privado de Recife-PE. Id on Line Rev. Psic (on-line) [Internet]. 2016 [acesso em 24 jan 2020]; 10(30):Sup.2. Disponível em: https://idonline.emnuvens.com.br/id/article/view/461.

14. Ministério da Saúde (BR). Portaria GM/MS n. ${ }^{\circ} 2848$ de 06 de novembro de 2007. Publica tabelas de Procedimentos, Medicamentos, Órteses e Próteses e Materiais Especiais - OPM do Sistema Único de Saúde [Internet]. Brasília (DF): MS, 2007 [acesso em 24 jan 2020]. Disponível em: http://bvsms.saude.gov.br/bvs/ saudelegis/gm/2007/prt2848_06_11_2007.html.

15. Ministério Da Saúde, Secretaria de Atenção à Saúde, Departamento de Regulação, Avaliação e Controle de Sistemas (BR). Manual Técnico Operacional do Sistema de Informação Hospitalar - Orientações Técnicas [Internet]. Brasília (DF): MS, 2012 [acesso em 24 jan 2020]. Disponível em: http://bvsms.saude.gov. br/bvs/publicacoes/manual_tecnico_sistema_informacao_hospitalar_sus.pdf.

16. Brasil. Portaria n. ${ }^{\circ} 1302$, de $1^{\circ}$ de agosto de 2017 . Redefine os critérios para aquisição, recebimento, utilização, monitoramento, controle e gerenciamento de OPME pelos hospitais e institutos federais subordinados à Secretaria de Atenção à Saúde do Ministério da Saúde (SAS/MS) [Internet]. Brasília (DF): BR, 2017 [acesso em 24 jan 2020]. Disponível em: http://bvsms.saude.gov.br/bvs/ saudelegis/sas/2017/prt1302_02_08_2017.html.

17. Brasil. Lei n. ${ }^{\circ} 8666$, de 21 de junho de 1993. Regulamenta 0 art. 37, inciso XXI, da Constituição Federal, institui normas para Licitação e Contratos da Administração Pública e dá outras providências [Internet]. Brasília (DF): BR, 2993 [acesso em 24 jan 2020]. Disponível em: http://www.planalto.gov.br/ccivil_03/leis/ I8666cons.htm.

18. Agência Nacional De Vigilância Sanitária (BR). Resolução RDC n. ${ }^{\circ} 14$, de 5 de abril de 2011. Institui o regulamento técnico com os requisitos para agrupamento de materiais de uso em saúde para fins de registro e cadastro na ANVISA e adota etiquetas de rastreabilidade para produtos implantáveis [Internet]. Brasília (DF): Anvisa, 2011 [acesso em 24 jan 2020]. Disponível em: http://portal. anvisa.gov.br/documents/33880/2568070/rdc0014_05_04_2011. pdf/90c4b4d2-ed6b-4145-bb02-cea742d3ef01.

19. Conselho Federal de Medicina (BR). Resolução n. ${ }^{\circ}$ 1804/2006, de 20 de dezembro de 2006. Estabelece normas para a utiliza- ção de materiais de implante [Internet]. Brasília (DF): CFM, 2006 [acesso em 24 jan 2020]. Disponível em: https://sistemas.cfm.org. $\mathrm{br} /$ normas/visualizar/resolucoes/BR/2006/1804.

20. Conselho Federal de Odontologia (BR). Resolução n. ${ }^{\circ}$ $115 / 2012$, de 3 de abril de 2012. Disciplina a prescrição de materiais de implante, órteses e próteses, e determina arbitragem de conflitos [Internet]. Brasília (DF): CFO, 2012 [acesso em 24 jan 2020]. Disponível em: http://www.crosp.org.br/uploads/paginas/ 05c3dd25d7da8f204e6bfed435990cfb.pdf.

21. Agência Nacional de Saúde Suplementar (BR). Resolução Normativa -NR n. ${ }^{\circ} 424$, de 26 de junho de 2017. Dispõe critérios para a realização de Junta Médica ou Odontológica formada para dirimir divergência técnico assistencial sobre procedimento ou evento em saúde a ser coberto pelas operadoras de planos de assistência à saúde [Internet]. Brasília (DF): ANS, 2017 [acesso em 24 jan 2020]. Disponível em: http://www.ans.gov.br/component/ legislacao/?view=legislacao\&task=TextoLei\&format $=$ raw\&id=M$\mathrm{zQzOQ}==$.

22. Agência Nacional de Saúde Suplementar. Resolução Normativa - RN n. ${ }^{\circ}$ 428, de 7 de novembro de 2017. Atualiza o Rol de Procedimentos e Eventos em Saúde que constitui a referência básica para cobertura assistencial mínima nos planos privados na assistência à saúde [Internet]. Brasília (DF): ANS, 2017 [acesso em 24 jan 2020]. Disponível em: http://www.ans.gov.br/component/legislacao/?view=legislacao\&task=TextoLei\&format=raw\&i$\mathrm{d}=\mathrm{MzUwMg}==$.

23. Agência Nacional de Vigilância Sanitária (BR). Resolução RDC n. ${ }^{\circ} 156$, de 11 de agosto de 2006. Dispõe sobre o registro, rotulagem e re-processamento de produtos médicos, e dá outras providências [Internet]. Brasília (DF): Anvisa, 2006 [acesso em 24 jan 2020]. Disponível em: http://portal.anvisa.gov.br/documents/33880/2568070/res0156 11 08_2006.pdf/74354a5e-3f52-455b-8de1-0c3d74e67067.

24. Agência Nacional De Vigilância Sanitária (BR). Resolução RDC n. ${ }^{\circ} 232$, de 20 de junho de 2018 . Dispõe sobre a obrigatoriedade de inclusão de código de barras linear ou bidimensional em etiquetas de rastreabilidade de stents para artérias coronárias, stents farmacológicos para artérias coronárias, e implantes para artroplastia de quadril e de joelho [Internet]. Brasília (DF): Anvisa, 2018 [acesso em 24 jan 2020]. Disponível em: http://portal.anvisa.gov.br/documents/10181/4580265/\%281\%29RDC_232_2018_ COMP.pdf/7c48d7e7-a534-49d7-bad0-66a0dd592e55.

25. Ventura PFEV, Freire EMR, Alves M. Participação do enfermeiro na gestão de recursos hospitalares. Rev. G\&S [Internet]. 2016 [acesso em 24 jan 2020]; 7(1):126-147. Disponível em: https:// periodicos.unb.br/index.php/rgs/article/view/3398.

26. Oliveira D, Jacinto SM, Siqueira CL. Auditoria de Enfermagem no Centro Cirúrgico. Revisa Administração em Saúde. RAS 2013;15 (61):151-58.

27. Alencar ACF. Aquisição e utilização das Órteses, Próteses e Materiais Especiais - OPME e os facilitadores do superfaturamento no sistema de saúde $-2016,56$ f Conclusão de Curso UNB, julho de 2016.

28. Magalhães A. 0 controle de estoque de órteses, próteses e materiais especiais (OPME) num hospital público de ensino. Monografia. [Bacharel em Administração] 2019 56f. Universidade Federal Fluminense.

29. Grossi LM,Pisa IV, Marin HF. Desenvolvimento e Avaliação de Aplicativo para Enfermeiros Auditores. Acta Paul Enferm [Internet]. 2014 [acesso em 24 jan 2020]; 27(2):179-85. Disponível em: https://www.scielo.br/scielo.php?pi$d=$ S0103-21002014000200015\&script $=$ sci_abstract\&tlng $=$ pt. 